\title{
TENSILE BOND STRENGTH OF ACRYLIC AND COMPOSITE DEN- TURE TEETH TO MILLED CAD/CAM RESINS
}

\author{
Ahmed E. El-gazzar", Mohamed A. Masoud ${ }^{* *}$, Mostafa I. Fayad ${ }^{* * *}$, Mohamed A. Helal $^{* * * *} \cdot$
}

\begin{abstract}
Objective: was to evaluate the effect of different surface treatments on the tensile bond strength of two different types of artificial teeth to CAD/CAM denture base. Materials and Methods: 160 specimens were fabricated and divided into two main groups according to the denture base material; Group (A) for conventional denture base (HCAR denture base) and Group (B) for CAD/ CAM denture base. According to the artificial teeth each group of denture base was subdivided into two subgroups, subgroup (I) for conventional acrylic denture teeth and subgroup (II) for composite resin denture teeth. According to the surface treatment each subgroup of artificial teeth was subdivided into four subgroups as following: Subgroup 1: no surface treatment (control group). Subgroup 2: sandblasting with 250-micron alumina particles. Subgroup 3: roughening with a diamond bur. Subgroup 4: specimens were treated by dichloromethane. Results: The results showed that Pre-polymerized CAD\CAM acrylic resin denture bases specimens exhibited non-significant lower bond strength than HCAR denture base specimens ( $p>0.05)$, acrylic resin denture teeth demonstrated higher bond strength to denture bases than composite resin denture teeth $(\mathrm{p} \leq 0.05)$. Conclusion: the Pre-polymerized CADICAM acrylic resin denture bases specimens exhibited non-significant lower bond strength than HCAR denture base specimens, and acrylic resin denture teeth demonstrated higher bond strength to denture bases than composite resin denture teeth, the bond strength of the denture teeth treated with both dichloromethane and sandblasting was improved while the bond strength of the denture teeth treated by roughening with diamond bur was decreased.
\end{abstract}

KEYWORDS: CAD/CAM denture base, tensile bond strength, acrylic denture teeth, composite resin denture teeth, surface treatment.

\section{INTRODUCTION}

The most common cause of the elderly people seek dental treatment is for the replacement of missing teeth. Although the number of edentulous people has decreased, there are still many patients demanding treatment that requires complete dentures. Different materials and fabrication techniques have been used to prepare dentures. An acrylic resin denture base material has been available to the dental profession for over 60 years. Acrylic resin has enjoyed a large popularity attributed to its simple processing technique and low cost of fabrication process. Although materials with superior properties have been introduced to the market, acrylic resin is still the most popular choice ${ }^{(1)}$. However, there are numerous disadvantages associated with fabrication

\footnotetext{
* Dentist, Ministry of Health and Population, Tanta, Egypt

** Department of Dental Biomaterial, Faculty of Dental Medicine, Boys, Cairo, Al-Azhar University

***Associate Professor, Department of Removable Prosthodontics, Faculty of Dental Medicine, Boys, Cairo, Al-Azhar University.

**** Professor, Head of Department of Removable Prosthodontics, Faculty of Dental Medicine, Boys, Cairo, Al-Azhar University
}

•Corresponding author: mhelal@azhar.edu.eg

DOI: $10.21608 /$ ajdsm.2020.36330.1086 
of acrylic resin complete dentures, such as the time consuming fabrication both for the dentist and the patient due to multiple appointments required, the laboratory costs and liability to break during service $^{(2)}$.

CAD/CAM technology may be used for fabrication of complete dentures in as few as two clinical visits. The first clinic visit includes impressions, determination of occlusal vertical dimension (OVD), registration of maxillomandibular relationships (MMR) and facial esthetics and tooth mold/shade selection. The second visits are for denture delivery and adjustment ${ }^{(3)}$.

Acrylic teeth are the most popular artificial teeth for denture constructions. They have many advantages, such as chemical bond with acrylic denture base, high fracture resistance, can be easily ground and polished, and minimal abrasion of opposite dentition. But certainly, it has some disadvantages. Recent research shows that $30 \%$ of denture repairs attribute to bond failure between acrylic-teeth and denture base resin ${ }^{(4)}$. Composite resin denture teeth were developed in the 1980s in an effort to achieve greater wear resistance and bond strength to denture bases. However, they presented clinical problems such as poor bonding to denture base, as well as brittle properties ${ }^{(5)}$.

Several factors affect the bond between artificial denture teeth and the denture base resin, such as residual wax on the ridge lap area of the teeth, uncaring application of the separating medium during processing, insufficient accessible monomer during processing and the polymerization method used in the processing of denture base resins ${ }^{(6,7)}$. Failure of acrylic teeth to bond to denture base resin is still a common clinical problem in Prosthodontics. Hence, this study was aimed to evaluate the effect of different surface treatments on tensile bond strength of two different types of artificial teeth to milled CAD/ CAM denture base.

\section{MATERIALS AND METHODS}

A total of 160 specimens were fabricated and divided into two main groups according to the type of the denture base material (each of 80 specimens). Group (A) for conventional denture base (HCAR denture base) and Group (B) for CAD/CAM denture base. According to the artificial teeth each group of denture base was subdivided into two subgroups (each of 40 specimens), subgroup (I) for conventional acrylic denture teeth and subgroup (II) for composite resin denture teeth.

One hundred and sixty square-shaped slices of artificial teeth ( 80 of acrylic teeth and 80 of composite teeth) were prepared with a standardized size ( 5 × 5 x $2 \mathrm{~mm}$ ) adopted from previous study with modification ${ }^{(8)}$. The cutting procedure was done using a high precision saw (IsoMet 4000; Buehler, USA), with cooling system water, cool $30: 1$, speed $1000 \mathrm{rpm}$, feeding rate $5 \mathrm{~mm} / \mathrm{min}$ with $0.3 \mathrm{~mm}$ thickness Buehler disk, cool cutting fluid and anti-corrosive.

\section{The HCAR denture base specimens were fabri- cated as follows:}

The metal die was used to fabricate the wax pattern specimens (Cavex Holland B.V., Netherlands) of the denture base resin disc, then the tooth slices were fixed to wax specimens (acrylic tooth slice at one side and composite tooth slice at the other side), then they were invested in dental stone within metal flasks and then all waxes were melted away.

After that, the surface treatments were carried out on the exposed surfaces of investing teeth slices. According the surface treatment each subgroup of artificial teeth was divided into four subgroups as following: Subgroup 1: with no surface treatment. Subgroup 2: were treated by sandblasting with 250-micron alumina particles for 15 seconds, by using of the sandblaster (Renfert $\mathrm{GmbH}$, Germany). Subgroup 3: were treated by roughening with a diamond bur. Subgroup 4: were 
treated by dichloromethane (Tabark Chemicals Co. Cairo, Egypt) as organic solvent using micro brush applicator and left for 30 seconds before packing or cementation. Then HCAR denture base specimens were fabricated as conventional manner and according to manufactures instructions.

\section{The CAD/CAM denture base specimens were fabricated as follows:}

The CAD/CAM denture base discs were fabricated by using of one of the wax pattern specimens fabricated by the metal die which sprayed with scan spray (Dr. Mat Dental CAD/CAM White Scan Spray, Istanbul, Turkey). After that the optical 3D scanner (Dent lab 3d scanner Activity 855. Germany) was used to scan the specimen. Then the STL files were sent to the CAD software. The milling process in wet condition of prepolymerized resin acrylic pucks was carried out as usual using a 5-axis milling machine (CORiTEC 350i, imesicore, Eiterfeld, Germany).

For surface treatment, the tooth slices were fixed on impression compound disks which used as a positioning device. After softening of the impression compound disk with hot water the tooth slices were arranged on it.

Teeth denture base bonding was done using a silicone index (Elite HD+, Zhermack) which was formed using ten conventional denture base specimens which pressed in to polyvinyl siloxane putty material with glass slab (upper) in contact with tooth slices at one side against another glass slab (lower) until contact of teeth slices at another sides with the lower glass slab. After hardening of polyvinyl siloxane putty material, the conventional denture base specimens removed to make the index, which was used for bonding of $10 \mathrm{CAD} / \mathrm{CAM}$ denture base specimens.

The acrylic denture teeth slices were placed in the silicone index, then IvoBase CAD bonding agent (Wieland Dental, Germany) were applied with the application syringe, then, CAD/CAM denture base slices were placed and a bonding agent was applied. Composite denture teeth slices were then placed. After that the upper glass slab was placed and a load of $2 \mathrm{~kg}$ was used to ensure standardization of the load applied. Specimens were stored without strain for 12 hours at room temperature, then finished and polished.

\section{Testing the samples for bond strength evaluation:}

The tensile bond strength testing was carried out using a Universal Testing Machine (Instron crop, Canton, MA. USA). Two opposing Jacob's Chucks were used for tensile bond strength testing one fixed to the upper movable compartment of the testing machine used for holding the artificial tooth disc, while the other was fixed to the lower compartment used for holding the acrylic base disk testing. The machine was run at a cross head speed of $0.5 \mathrm{~mm} / \mathrm{min}$ until de-bonding. The load at which the debonding occurred was recorded for each specimen (Fig. 1).

Tensile bond strength was calculation by dividing the load at debonding over the bonded area to convert the Newton value into megapascal (MPa) value.

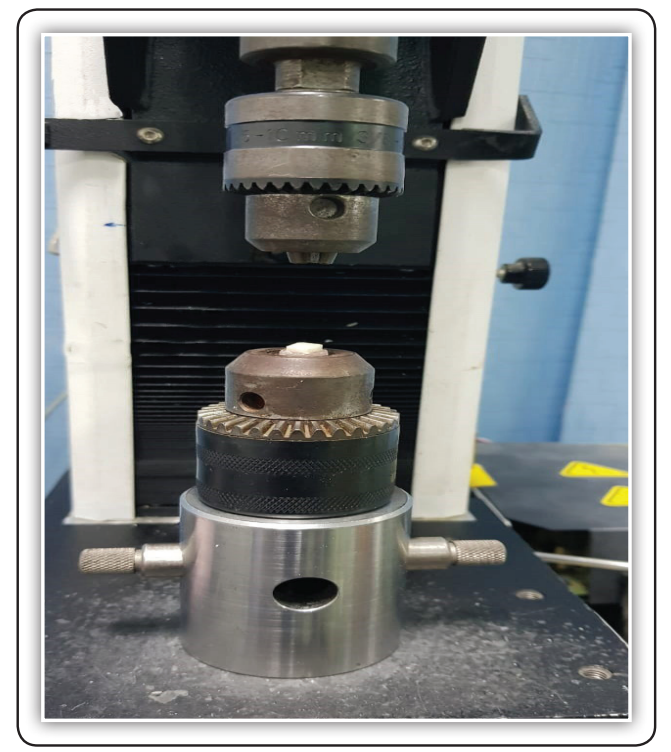

FIG (1) The sample on universal testing machine for tensile bond strength testing 
Data were collected, tabulated, subjected to Statistical analysis using ANOVA test and Tukey's post-hoc test for pairwise comparisons when the ANOVA test showed significant. Three-way ANOVA was used to show the effect of each variable on bond strength (denture base type, teeth type and surface treatment). The significance level was set at $\mathrm{P} \leq$ 0.05 and $95 \%$ Confidence interval.

\section{RESULTS}

Descriptive statistics of tensile bond strength (MPa) showing mean values and standard deviation for both denture base materials as a function of denture teeth and surface treatment are summarized in table (1). For group (A): Subgroup (I): the highest bond strength mean value was recorded in AI4 subgroup (14.09 $\pm 0.62 \mathrm{MPa}$ ) followed by AI3 subgroup mean value $(13.29 \pm 1.59 \mathrm{MPa})$ then AI1 subgroup means value $(13.23 \pm 2.87 \mathrm{MPa})$ while the lowest bond strength mean value was recorded in AI2 subgroup (11.23 $\pm 2.46 \mathrm{MPa})$. This difference between subgroups was statistically non-significant as proved by ANOVA test $(\mathrm{p}=0.09>0.05)$.

Subgroup (II): the highest bond strength mean value was recorded in AII1 subgroup (9.498 \pm 0.91 $\mathrm{MPa}$ ) followed by AII2 subgroup mean value $(6.913 \pm 1.08 \mathrm{MPa})$ then AII4 subgroup mean value $(6.076 \pm 0.85 \mathrm{MPa})$ while the lowest bond strength mean value was recorded in AII3 subgroup $(5.859 \pm 2.65 \mathrm{MPa})$. This difference between subgroups was statistically significant as proved by ANOVA test $(\mathrm{p}=0.0007<0.05)$. Pairwise Tukey's post-hoc test showed non-significant $(\mathrm{p}>0.05)$ difference only between AII2, AII4 and AII3 subgroups, (table 1).

For group (B): Subgroup (I): the highest bond strength mean value was recorded in BI4 subgroup $(13.46 \pm 1.96 \mathrm{MPa})$ followed by BI2 subgroup mean value $(12.45 \pm 1.61 \mathrm{MPa})$ then $\mathbf{B I 3}$ subgroup mean value $(10.96 \pm 1.78 \mathrm{MPa})$ while the lowest bond strength mean value was recorded in BI1 subgroup $(10.42 \pm 1.99 \mathrm{MPa})$. This difference between subgroups was statistically significant as proved by ANOVA test $(\mathrm{p}=0.0198<0.05)$. Pairwise Tukey's post-hoc test showed non-significant $(\mathrm{p}>0.05)$ difference only between BI4 and BI2, and BI3 and BI1 subgroups.

Subgroup (II): the highest bond strength mean value was recorded in BII2 subgroup (8.842 \pm 1.16 $\mathrm{MPa}$ ) followed by a BII4 subgroup mean value $(7.789 \pm 1.77 \mathrm{MPa})$ then BII3 subgroup mean value $(5.199 \pm 1.31 \mathrm{MPa})$ while the lowest bond strength mean value was recorded in BII1 subgroup $(4.784 \pm 2.69 \mathrm{MPa})$. This difference between subgroups was statistically significant as proved by ANOVA test $(\mathrm{p}=0.001<0.05)$. Pairwise Tukey's post-hoc test showed non-significant $(\mathrm{p}>0.05)$ difference only between BII2 and BII4, and BIII and BII3 subgroups.

TABLE (1) Tensile bond strength results (Mean values \pm SDs) for both denture base materials as function of denture teeth and surface treatment

\begin{tabular}{|c|c|c|c|c|c|c|}
\hline \multirow{2}{*}{ Groups } & \multirow{2}{*}{ Subgroups } & \multicolumn{4}{|c|}{ Surface treatment subgroups } & \multirow{2}{*}{$\begin{array}{c}\text { ANOVA } \\
\text { P value }\end{array}$} \\
\hline & & Untreated & Alumina-blasting & Bur roughening & Dichloromethane & \\
\hline \multirow{2}{*}{$A$} & $I$ & $13.23^{\mathrm{A}} \pm 2.87$ & $11.23^{\mathrm{A}} \pm 2.46$ & $13.29^{\mathrm{A}} \pm 1.59$ & $14.09^{\mathrm{A}} \pm 0.62$ & $0.09 \mathrm{NS}$ \\
\hline & II & $9.498^{\mathrm{A}} \pm 0.91$ & $6.913^{\mathrm{B}} \pm 1.08$ & $5.859^{\mathrm{B}} \pm 2.65$ & $6.076^{\mathrm{B}} \pm 0.85$ & $0.0007 *$ \\
\hline \multirow{2}{*}{$\boldsymbol{B}$} & $I$ & $10.42^{\mathrm{B}} \pm 1.99$ & $12.45^{\mathrm{A}} \pm 1.61$ & $10.96^{\mathrm{B}} \pm 1.78$ & $13.46^{\mathrm{A}} \pm 1.96$ & $0.0198 *$ \\
\hline & II & $4.784^{\mathrm{B}} \pm 2.69$ & $8.842^{\mathrm{A}} \pm 1.16$ & $5.199^{\mathrm{B}} \pm 1.31$ & $7.789^{\mathrm{A}} \pm 1.77$ & $0.001 *$ \\
\hline
\end{tabular}

Different letter in the raw column indicating significance $(p<0.05) . \quad *$; significant $(p<0.05)$ $n s$; non-significant ( $p>0.05)$ 
Comparing Group (A) and Group (B): Within Subgroup (I) It was found that in all surface treatment subgroups, group (A) recorded higher tensile bond strength mean values than group (B) except in the subgroup (2). The differences were statistically non-significant $(\mathrm{p}>0.05)$ in the subgroup $(\mathbf{1}, \mathbf{4})$ and statistically significant $(\mathrm{p}<0.05)$, in the subgroup (3), while in surface treatment subgroup (2). Group (B) recorded statistically non-significant ( $\mathrm{p}>0.05$ ) higher tensile bond strength means values than group (A), (table 2).

Within Subgroup (II) It was found that in a subgroup (1), group (A) recorded statistically significant $(\mathrm{p}<0.05)$ higher tensile bond strength means values than group (B) while non-significant ( $\mathrm{p}>0.05)$ in the subgroup (3). Group (B) recorded statistically significant $(\mathrm{p}<0.05)$ higher tensile bond strength means values than group (A) in subgroups $(\mathbf{2}, \mathbf{4})$ as indicated by student t-test $(\mathrm{p}<0.05)$, (table 3 ).

Total effect of denture teeth on bond strength: Regardless to denture base or surface treatment, totally it was found that Subgroup (I) recorded statistically significant higher tensile bond strength mean value (12.39 $\pm 1.14 \mathrm{MPa}$ ) than Subgroup (II) mean value $(6.87 \pm 1.39 \mathrm{MPa})$ as indicated by threeway ANOVA test followed by pairwise Tukey's post-hoc tests $(\mathrm{P}=<0.0001<0.05)$, (table 4$)$.

TABLE (2) Comparison of tensile bond strength results (Mean values \pm SDs) between both denture base materials as a function of surface treatment within Acrylic teeth

\begin{tabular}{|c|c|c|c|c|c|}
\hline \multirow{2}{*}{ Subgroup } & \multirow{2}{*}{ Groups } & \multicolumn{4}{|c|}{ Surface treatment subgroups } \\
\cline { 3 - 6 } & & Untreated & Alumina-blasting & Bur roughening & Dichloromethane \\
\hline \multirow{2}{*}{ I } & $\boldsymbol{A}$ & $13.23^{\mathrm{A}} \pm 2.87$ & $11.23^{\mathrm{A}} \pm 2.46$ & $13.29^{\mathrm{A}} \pm 1.59$ & $14.09^{\mathrm{A}} \pm 0.62$ \\
\cline { 2 - 6 } & $\boldsymbol{B}$ & $10.42^{\mathrm{B}} \pm 1.99$ & $12.45^{\mathrm{A}} \pm 1.61$ & $10.96^{\mathrm{B}} \pm 1.78$ & $13.46^{\mathrm{A}} \pm 1.96$ \\
\hline \multirow{2}{*}{$\boldsymbol{t}$-test } & $\boldsymbol{P}$ value & $0.0544 \mathrm{NS}$ & $0.2909 \mathrm{~ns}$ & $0.0241^{*}$ & $0.4287 \mathrm{~ns}$ \\
\hline
\end{tabular}

Different letter in same column indicating significance $(p<0.05) . \quad *$; significant $(p<0.05)$

$n s$; non-significant $(p>0.05)$

TABLE (3) Comparison of tensile bond strength results (Mean values \pm SDs) between both denture base materials as a function of surface treatment within Composite teeth

\begin{tabular}{|c|c|c|c|c|c|}
\hline \multirow{2}{*}{ Subgroup } & \multirow{2}{*}{ Group } & \multicolumn{4}{|c|}{ Surface treatment subgroups } \\
\cline { 3 - 6 } & & Untreated & Alumina-blasting & Bur roughening & Dichloromethane \\
\hline \multirow{2}{*}{ II } & $\boldsymbol{A}$ & $9.498^{\mathrm{A}} \pm 0.91$ & $6.913^{\mathrm{B}} \pm 1.08$ & $5.859^{\mathrm{B}} \pm 2.65$ & $6.076^{\mathrm{B}} \pm 0.85$ \\
\cline { 2 - 6 } & $\boldsymbol{B}$ & $4.784^{\mathrm{B}} \pm 2.69$ & $8.842^{\mathrm{A}} \pm 1.16$ & $5.199^{\mathrm{B}} \pm 1.31$ & $7.789^{\mathrm{A}} \pm 1.77$ \\
\hline \multirow{2}{*}{ t-test } & Pvalue & $0.0009^{*}$ & $0.007^{*}$ & $0.566 \mathrm{~ns}$ & $0.04^{*}$ \\
\hline
\end{tabular}

Different letter in same column indicating significance $(p<0.05) . \quad *$; significant $(p<0.05)$ $n s ;$ non-significant $(p>0.05)$ 
TABLE (4) Comparison between total tensile bond strength results (Mean values \pm SDs) as function of Denture teeth

\begin{tabular}{|c|c|c|c|c|}
\hline \multicolumn{2}{|c|}{ Variable } & Mean \pm SD & $\begin{array}{c}\text { Tukey's } \\
\text { rank }\end{array}$ & $\begin{array}{c}\text { Statistics } \\
\text { (P value) }\end{array}$ \\
\hline \multirow{2}{*}{$\begin{array}{c}\text { Denture } \\
\text { teeth }\end{array}$} & Subgroup (I) & $12.39 \pm 1.14$ & A & \\
\cline { 2 - 5 } & Subgroup (II) & $6.87 \pm 1.39$ & B & $<0.0001^{*}$ \\
\hline
\end{tabular}

*; significant $(p<0.05)$

$n s$; non-significant ( $p>0.05)$

Total effect of denture base on bond strength: Regardless to teeth or surface treatment, totally it was found that the group (A) recorded statistically non-significant higher tensile bond strength mean value $(10.02 \pm 1.6 \mathrm{MPa})$ than group (B) mean value $(9.24 \pm 1.73 \mathrm{MPa})$ as indicated by three-way ANOVA test followed by pairwise Tukey's post-hoc tests $(\mathrm{P}=0.1462>0.05)$.

Total effect of surface treatment on bond strength: Regardless to denture base or teeth, totally the highest tensile bond strength mean value was recorded in subgroup (4) $(10.35 \pm 3.42 \mathrm{MPa})$ followed by subgroup (2) mean value $(9.859 \pm 1.98$ $\mathrm{MPa})$ then subgroup (1) mean value $(9.485 \pm 2.35$ $\mathrm{MPa}$ ) while the lowest tensile bond strength mean value was recorded in subgroup (3), $(8.828 \pm 3.29$ $\mathrm{MPa})$. This difference between subgroups was statistically non-significant as proved by three-way ANOVA test $(\mathrm{p}=0.2334>0.05)$.

\section{DISCUSSION}

Despite the popularity of acrylic resin as denture base material, there are many drawbacks of such material. Evolution of computer-aided technology in the field of complete denture fabrication is expected to overcome the problems related to conventional fabrication techniques.

Acrylic teeth are the most popular artificial teeth for denture constructions. There are many disadvantages of such material. Composite resin denture teeth were developed in an attempt to obtain greater wear resistance and bond strength to denture bases.

The debonding of artificial teeth from the denture base is one of the most common causes of prosthesis failure. Several methods were used to improve the bonding of teeth to denture bases which can be classified into chemical and mechanical modification of the ridge lap area or a combination of both ${ }^{(9)}$. Three different types of the surface treatment (roughening with a diamond bur, sandblasting with aluminum oxide particles, the use of organic solvents as dichloromethane) are applied in the present study of the denture teeth ridge lap area prior to denture base processing of conventional or CAD/CAM acrylic resin denture base.

In a tensile bond test, a load will be applied on both the sides of the test specimen. The specimen can be grasped by passive or active gripping methods. The Active gripping method involves mechanical attachment of specimen to gripping device, such as glue or clamps, while in passive gripping method, specimen is placed in a testing device without the aid of glue or mechanical gripping. In the tensile test, stresses across the interface is much more homogeneous than in shear and, therefore, maximum principal stress values are much closer to the nominal strength ${ }^{(10)}$.

Obtained results demonstrated that the tensile bond strength of the Pre-polymerized CADICAM acrylic resin denture base to the artificial teeth is non-significantly less than that of the HCAR denture base and artificial teeth ( $>00.05)$.

The tensile bond strength of acrylic teeth to denture bases (conventional group and CAD-CAM group) were higher than that of composite teeth $(p \leq 0.05)$. The results of this study are in agreement with Ghahramani et al ${ }^{(11)}$ who compared the bond strength of composite and acrylic teeth to heatcured and auto-polymerized acrylic denture base 
and reported that the bond strengths of acrylic teeth to HCAR were statistically higher than those of composite teeth. These results can be explained by the ability of acrylic teeth to produce a chemical bond to the denture base resin. The chemical bonding between acrylic teeth and the polymermonomer dough occurs by absorption of monomer through the surface layers of teeth ${ }^{(5,12)}$.

The results of the present study revealed that the tooth surface treatment by dichloromethane recorded the highest tensile bond strength values than the other groups $(\mathrm{p} \leq 0.05)$. These results were in agreement with Dogan et al ${ }^{(13)}$ who studied the tensile bond strength of a highly cross-linked denture tooth to the compression-molded and injection-molded denture base polymers and reported that treating tooth surfaces with dichloromethane significantly improved the bond strengths of auto and heat-polymerized resins. These results can be explained by dichloromethane is an organic and non-polymerizable solvent, which swells the surface and permits a diffusion of polymerizable material. The strength of the bond depends upon the degree of penetration of the solvent and the strength of the interwoven polymer network formed thereafter. Dichloromethane preparation can create surface pores and channels approximately $1 \mu \mathrm{m}$ in diameter on conventional acrylic resin teeth, and these channels tend to interconnect frequently. The micro roughness created by dichloromethane treatment on denture tooth surfaces increased the mechanical retention thereby improving the bond strength. Nagai et $\mathrm{al}^{\left({ }^{(14)}\right.}$ stated that the scanning electron microscope pictures of the denture tooth surfaces treated with dichloromethane revealed pores, channels, superficial crack propagation as well as the formation of numerous pits approximately $2 \mu \mathrm{m}$ in diameter probably representing the spaces previously occupied by resin polymer. Such a surface topography suggests micromechanical retention as a mechanism to explain the advantage of dichloromethane in improving bonding.
Obtained results demonstrated that tooth surface treatment by sandblasting with aluminum oxide particles recorded a higher tensile bond strength values than the control group $(\mathrm{p} \leq 0.05)$. This was in agreement with Gowda et al ${ }^{(15)}$ who evaluated the effect of pre-processing mechanical treatment of the ridge lap surface of acrylic teeth on the bond strength between denture base resin and acrylic teeth and reported that the control group obtained lower bond strength values than the sandblasting and grinding surface treatment groups. This improvement in bond strength may be due to the using of sandblasting led to increasing the surface roughening that increased the surface area available for bonding where some mechanical interlocking might have occurred across the interface. It is also possible that the increased magnitude of bond strength might have occurred due to enhanced surface reactivity as a result of the removal of a saturated surface layer of sand blasting and the exposure of the subsurface layer of a higher free surface energy available for bonding ${ }^{(16)}$. In fact, the free surface energy of the newly sandblasted resin surface created by sandblasting with Alumina is undoubtedly higher than that of the untreated surface, which may be a reason why roughening improves bonding ${ }^{(17)}$.

Obtained results demonstrated that tooth surface treatment by roughening with a diamond bur recorded a lower tensile bond strength than control group ( $\mathrm{p} \leq 0.06$ ). This might be due to the surface features of roughening produced by using a diamond bur was not same as the roughening produced using other methods. These results were in disagreement with Gowda et al ${ }^{(15)}$ who reported that the control group obtained lower bond strength values than the sandblasting and grinding surface treatment groups.

The results of the current study were at variance with other studies ${ }^{(3,15,18,19)}$ this may be due to different experimental design, testing, condition and materials used. 


\section{CONCLUSION}

Within the limitations of this study, the following conclusions could be drawn:

- Pre-polymerized CAD $\backslash C A M$ acrylic resin denture base specimens exhibited a nonsignificant lower tensile bond strength than conventional heat-cured acrylic resin denture base specimens.

- Acrylic resin denture teeth demonstrated higher tensile bond strength to denture bases than composite resin denture teeth.

- Using the dichloromethane or sandblasting with aluminum oxide particles as surface treatment of the ridge lap surface of the artificial denture teeth improved the tensile bond strength between teeth and denture bases. While roughening of the ridge lap surface of the artificial denture teeth with a diamond bur failed to improve the tensile bond strength.

\section{REFERENCES}

1. D.B. Barbosa et al. Bond strength of denture teeth to acrylic resin: effect of thermocycling and polymerisation methods. Gerodontology. 2008;25: 237-44.

2. Bidra AS, Taylor TD, Agar JR. Computer-aided technology for fabricating complete dentures: systematic review of historical background, current status, and future perspectives. J Prosthet Dent. 2013; 109: 361-6.

3. Baba NZ, AlRumaih HS, Goodacre BJ, Goodacre CJ. Current techniques in CAD/CAM denture fabrication. Gen Dent. 2016; 64: 23-8.

4. Yadav NS, Somkuwar S, Mishra SK, Hazari P, Chitumalla R, Pandey SK. Evaluation of bond strength of acrylic teeth to denture base using different polymerization techniques: A comparative study. J Int Oral Health 2015; 7: 54-56.

5. Suzuki S. In vitro wear of nano-composite denture teeth. J Prosthodont. 2004; 13: 238-43.

6. Rupp NW, Bowen RL, Paffenberger GC. Bonding cold curing denture base acrylic resin to acrylic resin teeth. J Am Dent Assoc. 1971; 83: 601-6.
7. Cunningham JL, Benington IC. An investigation of the variables which may affect the bond between plastic teeth and denture base resin. J Dent. 1999; 27: 129-35.

8. Stoia1 AE, CS, MP, Enescu1 M, AT, ROR, et al. Tensile testing, a method used to demonstrate the effect of organic solvents on acrylic teeth denture base resin bond strength. J Int Biology and Biomedical Engineering. 2011; 5: 9-17.

9. Schneider RL, Curtis ER, Clancy JM. Tensile bond strength of acrylic resin denture teeth to a microwave- or heat-processed denture base. J Prosthet Dent. 2002; 88: 145-50.

10. Van Noort R, Noroozi S, Howard IC, Cardew G. A critique of bond strength measurements. J Dent. 1989; 17: 61-7.

11. Ghahramani L, Shahabi S, Amirjan A, Fazel A. Comparison of bond strength of composite and acrylic teeth to heat-cured and auto-polymerized acrylic denture base. J Dent Med Tehran Univ Med Sci. 2010;23: 215- 226.

12. Rupp NW, Bowen RL, Paffenberger GC. Bonding cold curing denture base acrylic resin to acrylic resin teeth. J Am Dent Assoc. 1971; 83: 601-6.

13. Arife Dogan, Turan Korkmaz, Orhan Murat Dogan, Selda Keskin. Tensile Bond Strength of a Highly Cross-Linked Denture Tooth to the Compression-Molded and InjectionMolded Denture Base Polymers. INT J ADHES ADHES. 2009; 85: 953-970.

14. E Nagai, K Otani, Y Satoh, S Suzuki. Repair of denture base resin using woven metal and glass fiber: effect of methylene chloride pretreatment. J Prosthet Dent. 2001; 85: 496-500.

15. Gowda, et al. Comparative Evaluation of Effect of PreProcessing Surface Treatment of Acrylic Teeth on Bonding with Denture Base Resins: An In Vitro Study. IJOCR. 2018; 6:13-18.

16. Bahrani F, Khaledi AA. Effect of surface treatments on shear bond strength of denture teeth to denture base resins. Dent Res J. 2014;11: 114-8.

17. Fletcher A M, Al-Mulla M A, Amin W M, Dodd AW, itchie $\mathrm{G}$ M. A method of improving the bonding between artificial teeth and PMMA. J Dent. 1985; 13: 102-8.

18. Choi et al. Bond Strength of Denture Teeth to Heat-Cured, CAD/CAM and 3D Printed Denture Acrylics. J Prosthodont. 2019;28: 497-503.

19. Azad aa, siddiqui az, jawad a, zia m, ali t. Effect of mechanical modification of acrylic resin denture teeth bonded to acrylic denture base. PODJ. 2012; 32 :149-53. 